\title{
Pseudo-precocious Puberty Associated with an Adrenocortical Tumor in a Young Child
}

\author{
Shahd E. Kafi ${ }^{1}$, Eid Alagha ${ }^{1}$, Mohamed Abdelmaksoud Shazly ${ }^{1}$, Abdulmoein Al-Agha ${ }^{1}$ \\ 1. Pediatrics, King Abdulaziz University Hospital, Jeddah, SAU
}

Corresponding author: Abdulmoein Al-Agha, aagha@kau.edu.sa

\begin{abstract}
Precocious puberty is commonly observed in pediatric practice due to different causes, including adrenal tumors. Adrenocortical tumors are rare in children and are characterized by an androgenic hormonal excess that causes pseudo-precocious puberty. We present the case of a four-year-old boy with a history of penile enlargement associated with the growth of pubic hair, facial acne, and three-years advanced bone age. Based on hormonal assays, the diagnosis of pseudo-precocious puberty was confirmed. Abdominal magnetic resonance imaging (MRI) revealed a right-sided, retroperitoneal, well-defined adrenal tumor. This case report emphasizes the aim to increase the awareness of adrenocortical tumor as a rare cause of pseudoprecocious puberty in young children.
\end{abstract}

Categories: Endocrinology/Diabetes/Metabolism, Pediatrics

Keywords: adrenal tumor, young children, pseudoprecocious, puberty, pseudo-precocious

\section{Introduction}

Although adrenocortical tumors (ACTs) can occur at any age, they are rare in childhood [1]. The first case of childhood ACT was reported in 1865 [2]. The ACT is a rare neoplasm that accounts for about $0.2 \%$ of all tumors affecting children and approximately $6 \%$ of all adrenal tumors observed in the pediatric group [3]. The annual incidence of ACT in children under 15 years of age is extremely rare, ranging from 0.3-0.5 cases per million [4]. However, the incidence varies across various geographical regions; for example, in the United States and Europe, it accounts for 0.3-0.38 cases per million [4-5]. In comparison, 10-15 times more cases are diagnosed in Brazil than in the rest of the world [6-7]. Almost 50\% of ACT cases are associated with syndromes, and the two main syndromes that were reported included the Li-Fraumeni syndrome that resulted from alterations of the tumor suppressor gene p53 in chromosome 17 and the Beckwith-Weidman syndrome that resulted from the effect of the region located in chromosome $11 \mathrm{p} 15[2,8-9]$. ACT was categorized as functional (hormone-secreting), which is most commonly found in children and adolescents, or non-functional (silent), which is usually found in adults with symptoms of abdominal discomfort or back pain caused by the large mass of the tumor [10-11]. ACT can be benign or malignant [3]. The most common clinical presentation of ACT in children is pseudo-precocious puberty, which is observed

Received 12/16/2019

Review began 12/16/2019 Review ended 12/19/2019 Published 12/22/2019

\section{(c) Copyright 2019}

Kafi et al. This is an open access article distributed under the terms of the Creative Commons Attribution License CC-BY 3.0., which permits unrestricted use, distribution, and reproduction in any medium, provided the original author and source are credited. malignancy should not be underestimated in this age group [2]. We report the case of a four-year-old boy who presented with pseudo-precocious puberty caused by ACT, which is rare in children.

\section{Case Presentation}

A four-year-old boy presented to the pediatric endocrinology clinic with the appearance of pubic hair in conjunction with an increase in penile length for two months. He was delivered vaginally after a full-term pregnancy and had no medical or surgical histories. There was no family history of endocrine tumors or early puberty. Systemic examinations, including vital signs, were unremarkable. He had facial acne on his forehead and cheeks (Figure 1) with no skin hyperpigmentation. His Tanner staging of pubic hair and genitalia was stage III. The volume of both the testes was $2 \mathrm{ml}$, and his stretched penile length (SPL) was 7.5 $\mathrm{cm}$ (Figure 2). His serum hormonal assays are presented in Table 1 and show low basal levels of folliclestimulating hormone (FSH), luteinizing hormone (LH), and 17-hydroxyprogesterone and elevated levels of testosterone and dehydroepiandrosterone sulfate (DHEA-S). Gonadotropin-releasing hormone (GnRH) stimulation test showed a negative response. The bone age was advanced by three years. Therefore, the diagnosis of pseudo-precocious puberty was confirmed. Abdominal magnetic resonance imaging (MRI) revealed a right-sided retroperitoneal adrenal mass (Figure 3). The adrenocortical tumor was diagnosed based on clinical manifestations and imaging. 


\section{Cureus}

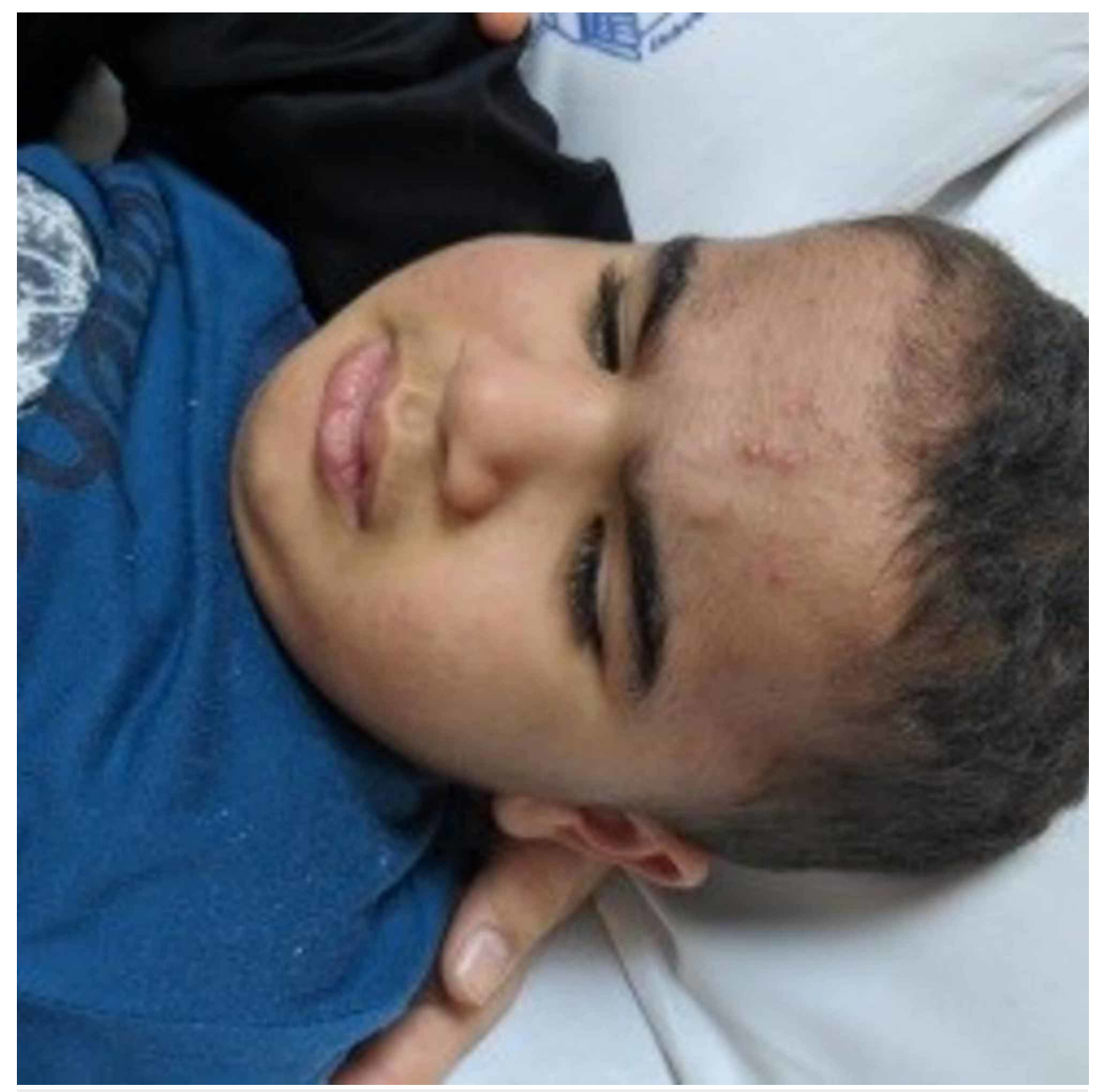

FIGURE 1: Facial acne was observed as a part of pubertal changes 


\section{Cureus}

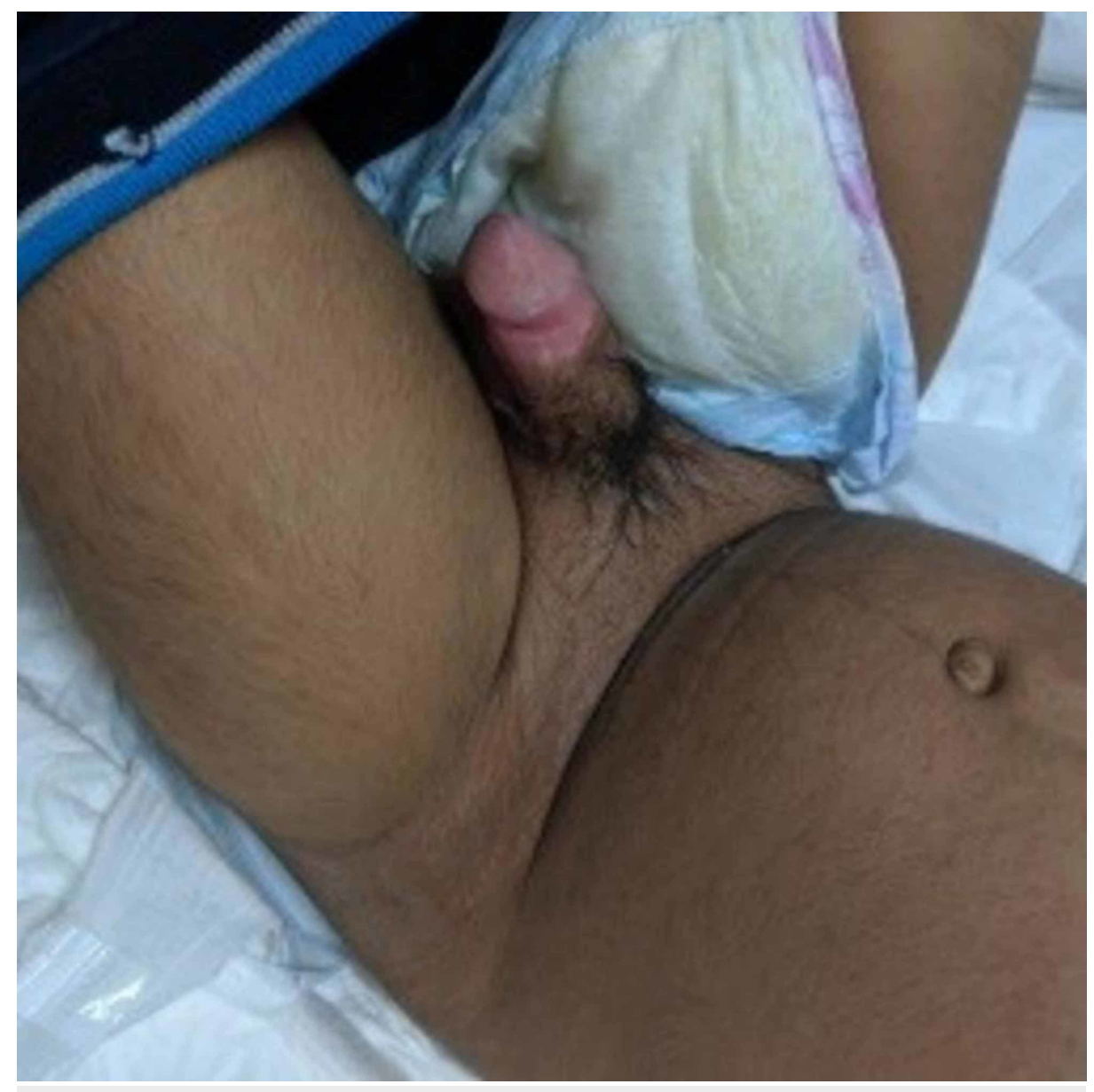

FIGURE 2: Patient with erected penis with increase in penile width, length, and pubic hair 


\section{Cureus}

\begin{tabular}{|c|c|c|}
\hline Test & Date & Result \\
\hline \multirow{7}{*}{ Follicular stimulating hormone } & $0 \mathrm{~min}$ & 0.2 \\
\hline & $15 \mathrm{~min}$ & 0.4 \\
\hline & $30 \mathrm{~min}$ & 0.3 \\
\hline & $45 \mathrm{~min}$ & 0.4 \\
\hline & $60 \mathrm{~min}$ & 0.3 \\
\hline & $90 \mathrm{~min}$ & 0.5 \\
\hline & $120 \mathrm{~min}$ & 0.6 \\
\hline \multirow{7}{*}{ Luteinizing hormone } & $0 \mathrm{~min}$ & 0.2 \\
\hline & $15 \mathrm{~min}$ & 0.3 \\
\hline & $30 \mathrm{~min}$ & 0.2 \\
\hline & $45 \mathrm{~min}$ & 0.2 \\
\hline & $60 \mathrm{~min}$ & 0.2 \\
\hline & $90 \mathrm{~min}$ & 0.2 \\
\hline & $120 \mathrm{~min}$ & 0.2 \\
\hline \multirow{2}{*}{ Testosterone } & first & 39 \\
\hline & repeated & 33 \\
\hline $17 \mathrm{OH}$ progesterone & $18.8 \mathrm{ng} / \mathrm{ml}$ & Normal \\
\hline Alfa fetoprotein (AFP) & $4.45 \mathrm{ng} / \mathrm{ml}$ & normal \\
\hline Beta-human chorionic gonadotropin (BHCG) & $<1.2 \mathrm{iu} / \mathrm{ml}$ & normal \\
\hline
\end{tabular}

\section{TABLE 1: Results of the hormonal assay}

17-hydroxyprogesterone (17-OH progesterone); alfa fetoprotein (AFP); beta human chorionic gonadotropin (BHCG) 


\section{Cureus}

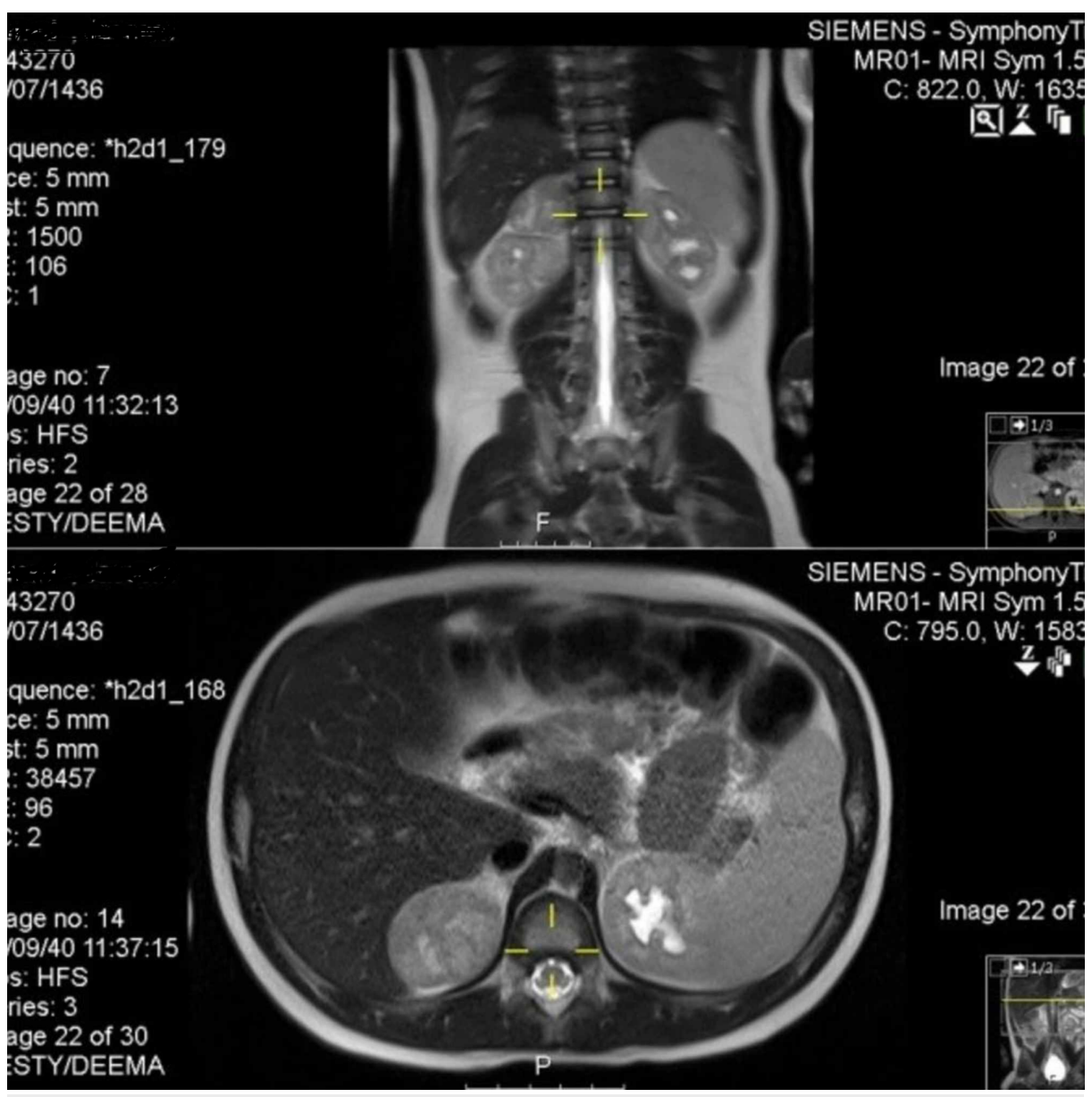

FIGURE 3: Magnetic resonance imaging showing an adrenal tumor

\section{Discussion}

Precocious puberty is defined as the presence of secondary sex characteristics before the age of eight in girls and nine in boys. These limits represent 2-2.5 standard deviations (SD) below the mean age of onset of puberty [14]. Precocious puberty is of two main types: central precocious puberty (CPP), which is gonadotropin dependent and caused by the early activation of the hypothalamic-pituitary-gonadal axis, and pseudo-precocious puberty, which is gonadotropin independent and results from the excess secretion of sex hormones from the gonads or adrenal glands [15]. There are several causes of pseudo-precocious puberty, including adrenal tumors, non-classical congenital adrenal hyperplasia, testicular tumors, germ cell tumors, McCune-Albright syndrome, familial male-limited precocious puberty (testotoxicosis), or exogenous sex steroid hormone usage. The clinical presentations of the two types of precocious puberty are markedly different, as CPP often presents with gonadal enlargement of testicles in males or ovaries in females, whereas pseudo-precocious puberty presents mainly with the early development of pubic and/or axillary hair. The dynamic stimulating test of the hypothalamic-pituitary-gonadal axis using a gonadotropinreleasing hormone $(\mathrm{GnRH})$ agonist has an essential and golden role in the differentiation of the two types of precocious puberty. Pubertal response by increasing the hormonal level of LH and FSH is usually observed in $\mathrm{CPP}$, while no response usually confirms pseudo-precocious puberty, as observed in this case.

Adrenocortical tumors (ACTs) can cause pseudo-precocious puberty by the secretion of excess androgenic hormones leading to virilization, which is the most common symptom of tumors in childhood. However, a late presentation of ACT could be seen with CPP secondary to the maturation of the hypothalamic-pituitary-gonadal axis. Female children are more affected than males, with a peak age of younger than four years [12]. The management of this disease is still challenging because of the limited number of reported cases. Nonclassical congenital adrenal hyperplasia (NCAH) causes androgen oversecretion, which leads to pseudo-precocious puberty with the development of early signs of puberty, including pubic hair, acne, and accelerating skeletal maturation [16]. This disease can be detected early in the neonatal period by screening for an elevated serum level of 17-hydroxyprogesterone. However, in this case, NCAH was excluded because of normal levels of 17-hydroxyprogesterone, cortisol, and

adrenocorticotropic hormone (ACTH). An abdominal MRI finding of unilateral tumor of the right adrenal gland confirms the diagnosis of ACT. 
A literature review of case reports revealed that virilization was considered a good clue for suspecting ACT, similar to the presentation in this case [11-13]. Razavi reported a 10-month-old boy diagnosed with ACT, who presented with sexual pubic hair, acne, and seborrhea dermatitis [3]. Another case of a two-year-old Indian boy presented with pubic hair and penile enlargement was reported

[1]. Ghazizadeh reported virilization in a two-year-old girl associated with ACT in 2013 [16]. However, discriminating benign tumors from malignant tumors does not depend on hormone secretions. A comprehensive evaluation of precocious puberty, including clinical manifestations, laboratory testing, and imaging, is important for reaching the final diagnosis.

\section{Conclusions}

Virilization of both sexes is an important manifestation of adrenocortical tumors, which is one of the rare causes of pseudo-precocious puberty. A high index of suspicion and an increased awareness of pediatricians play an important role in the early diagnosis and treatment of this disease.

\section{Additional Information \\ Disclosures}

Human subjects: Consent was obtained by all participants in this study. Conflicts of interest: In compliance with the ICMJE uniform disclosure form, all authors declare the following: Payment/services info: All authors have declared that no financial support was received from any organization for the submitted work. Financial relationships: All authors have declared that they have no financial relationships at present or within the previous three years with any organizations that might have an interest in the submitted work. Other relationships: All authors have declared that there are no other relationships or activities that could appear to have influenced the submitted work.

\section{References}

1. Meshram RM, Bhongade S, Patil S, Jadhav B, Laddha P: Precocious puberty associated with an adrenal tumor: a case report. Am J Med Case Rep. 2016, 4:354-356.

2. Ribeiro RC, Michalkiewicz EL, Figueiredo BC, et al.: Adrenocortical tumors in children. Braz J Med Biol Res. 2000, 33:1225-1234. 10.1590/s0100-879x2000001000013

3. Razavi Z, RastgooHaghi A: Precocious puberty associated with an adrenal tumor: a case report . Iran J Ped Hematol Oncol. 2016, 6:136-141.

4. Shirata NK, Sredni ST, Castelo A, et al.: Texture image analysis in differentiating malignant from benign adrenal cortical tumors in children and adults. Anticancer Res. 2009, 29:3365-3368.

5. Ciftci AO, Senocak ME, Tanyel FC, Büyükpamukçu N: Adrenocortical tumors in children. J Pediatr Surg. 2001, 36:549-554. 10.1053/jpsu.2001.22280

6. Ribeiro RC, Figueiredo B: Childhood adrenocortical tumours. Eur J Cancer. 2004, 40:1117-1126. 10.1016/j.ejca.2004.01.031

7. Figueiredo BC, Sandrini R, Zambetti GP, et al.: Penetrance of adrenocortical tumours associated with the germline TP53 R337H mutation. J Med Genet. 2006, 43:91-96. 10.1136/jmg.2004.030551

8. Wiedemann HR: Complexe malformatif familial avec hernie umbilicale et macroglossie, un "syndrome nouveau" [Article in French]. J Hum Genet. 1964, 13:223.

9. Li FP, Fraumeni Jr JF, Mulvihil JJ, Blattner WA, Dreyfus MG, Tucker MA, Miller RW: A cancer family syndrome in twenty-four kindreds. Cancer Res. 1998, 48:5358-5362.

10. Faizah MZ, Zuhanis AH, Rahmah R, Raja AA, Wu LL, Dayang AA, Zulfiqar MA: Precocious puberty in children: a review of imaging findings. Biomed Imaging Interv J. 2012, 8:6. 10.2349/biij.8.1.e6

11. Kim MS, Yang EJ, Cho DH, Hwang PH, Lee DY: Virilizing adrenocortical carcinoma advancing to central precocious puberty after surgery. Korean J Fam Med. 2015, 36:150-153. 10.4082/kjfm.2015.36.3.150

12. Michalkiewicz E, Sandrini R, Figueiredo B, et al.: Clinical and outcome characteristics of children with adrenocortical tumors: a report from the International Pediatric Adrenocortical Tumor Registry. J Clin Oncol. 2004, 22:838-845. 10.1200/JCO.2004.08.085

13. Cacciari E, Cicognani A, Pirazzoli P, et al.: Adrenocortical tumors in children: our experience with nine cases. Eur J Endocrinol. 1986, 279:264-274. 10.1530/acta.0.112s264

14. Definition, etiology, and evaluation of precocious puberty . (2016). https://www.uptodate.com/contents/definition-etiology-and-evaluation-of-precocious-puberty.

15. Witchel SF, Azziz R: Nonclassic congenital adrenal hyperplasia . Int J Pediatr Endocrinol. 2010, 2010:625105. $10.1155 / 2010 / 625105$

16. Ghazizadeh F, Ebadi M, Alavi S, Arzanian MT, Shamsian B, Jadali F: Adrenocortical carcinoma presenting with heterosexual pseudoprecocious puberty shortly after birth: case report and review. Ecancermedicalscience. 2013, 7:289. 10.3332/ecancer.2013.289 